\title{
Insight into the Scope and Mechanism for Transmetallation of Hy- drocarbyl Ligands on Complexes Relevant to C-H Activation.
}

\author{
Natalie H. Chan, ${ }^{\S, f,+}$ Joseph J. Gair, ${ }^{\ddagger,+}$ Michael Roy, ${ }^{\ddagger}$ Yehao Qiu, ${ }^{\ddagger}$ Duo-Sheng Wang, ${ }^{\ddagger}$ Landon J. Durak, ${ }^{\ddagger}$ Liwei \\ Chen, ${ }^{\ddagger}$ Alexander S. Filatov, ${ }^{\ddagger}$ Jared C. Lewis ${ }^{\S, *}$ \\ ${ }^{\S}$ Department of Chemistry, Indiana University, Bloomington, Indiana, 47401, United States. \\ ${ }^{\ddagger}$ Department of Chemistry, University of Chicago, Chicago Illinois, 60637, United States. \\ + These authors contributed equally to this work.
}

Supporting Information Placeholder

\begin{abstract}
We report the transmetallation of hydrocarbyl fragments $(\mathrm{Me}, \mathrm{Bn}, \mathrm{Ph})$ from a variety of organo-metallic complexes relevant to $\mathrm{C}-\mathrm{H}$ activation (Ir, Rh, W, Mo) to Pt(II) electrophiles. The scope of suitable hydrocarbyl donors is remarkable in that three different classes of organometallics with widely varying reactivity all undergo the same general reaction with $\mathrm{Pt}(\mathrm{II})$ electrophiles. A competitive substituent effect experiment reveals faster transmetallation of more electron rich hydrocarbyl groups. A sterochemical probe reveals that transmetallation to $\mathrm{Hg}$ (II) proceeds with retention of stereochemistry. This study suggests that transmetallation could provide a viable path for catalytic functionalization of stable complexes resulting from $\mathrm{C}-\mathrm{H}$ bond activation and other processes.
\end{abstract}

The activation of $\mathrm{C}-\mathrm{H}$ bonds to form organometallic compounds has been exploited to develop methods that allow for improved synthetic efficiency by conversion of $\mathrm{C}-\mathrm{H}$ bonds to desired functionality. ${ }^{1}$ Studies of stoichiometric $\mathrm{C}-\mathrm{H}$ activations that yield stable organometallic products form the basis for our current understanding of organometallic $\mathrm{C}-\mathrm{H}$ activation. ${ }^{2}$ These efforts have led to the identification of reactive intermediates, including those in Figure $1 \mathrm{~A}$, that promote $\mathrm{C}-\mathrm{H}$ cleavage under mild conditions. Functionalizing the resulting hydrocarbyl ligands under conditions compatible with catalytic $\mathrm{C}-\mathrm{H}$ functionalization, on the other hand, remains challenging. We hypothesized that the $\mathrm{C}-\mathrm{H}$ activation reactivity of intermediates like those in Figure 1A might be harnessed by coupling $\mathrm{C}-\mathrm{H}$ activation with one metal (M1) to functionalization on a second metal (M2) via transmetallation of the activated hydrocarbyl fragment as shown in Figure 1B. ${ }^{3,4}$ Indeed, there have been several reports in recent years showing transmetallation of hydrocarbyl fragment between two transition metal complexes after $\mathrm{C}-\mathrm{H}$ activation by $(\mathrm{M} 1)$ in similar systems, where $(\mathrm{M} 1)=\mathrm{Pd}(\mathrm{II}), \mathrm{Ag}(\mathrm{I})$ and $(\mathrm{M} 2)=$ $\mathrm{Pd}(\mathrm{II}), \mathrm{Au}(\mathrm{III}) .^{5}$ Although our efforts focus on transmetallation from organometallics related to $\mathrm{C}-\mathrm{H}$ activation, a better understanding of transmetallation between transition metals may open new avenues for coupling a wide range of organometallic reactivities via transmetallation between transition metals. ${ }^{6}$

The $\mathrm{C}-\mathrm{H}$ activation and functionalization reactivities in figure $1 \mathrm{~B}$ are well established, but transmetallation between two transition metals is much less understood. We previously reported that hydrocarbyl ligands on $\mathrm{Cp}^{*}\left(\mathrm{PMe}_{3}\right)$ Ir complexes can undergo transmetallation with $\mathrm{d}^{8} \mathrm{Pt}$ and $\mathrm{Pd}$ complexes ${ }^{3}$ and that this transmetallation process can be incorporated into Pd-catalyzed direct arylation reactions. ${ }^{4}$ Based on this reactivity, we next sought to explore the scope and mechanism of transmetallation of hydrocarbyl ligands from complexes relevant to $\mathrm{C}-\mathrm{H}$ activation to organometallic electrophiles. ${ }^{3,47}$ Herein, we show that a variety of complexes related to the intermediates in Figure 1A were competent hydrocarbyl donors in transmetallation to (cod) $\mathrm{Pt}(\mathrm{Me})(\mathrm{TFA})$ ( cod = cyclooctadiene, TFA = tri-fluoroacetate) (Figure 2). The scope of hydrocarbyl donors is striking for the diversity of suitable metals ( $\mathrm{Ir}, \mathrm{Rh}, \mathrm{W}, \mathrm{Mo}$ ) and the widely varying geometries, electronic structures, and divergent reactivities of the organometallic complexes. This finding opens the door for subsequent studies focused on exploiting this reactivity for catalysis and potentially enabling new approaches to functionalize unactivated $\mathrm{C}-\mathrm{H}$ bonds.
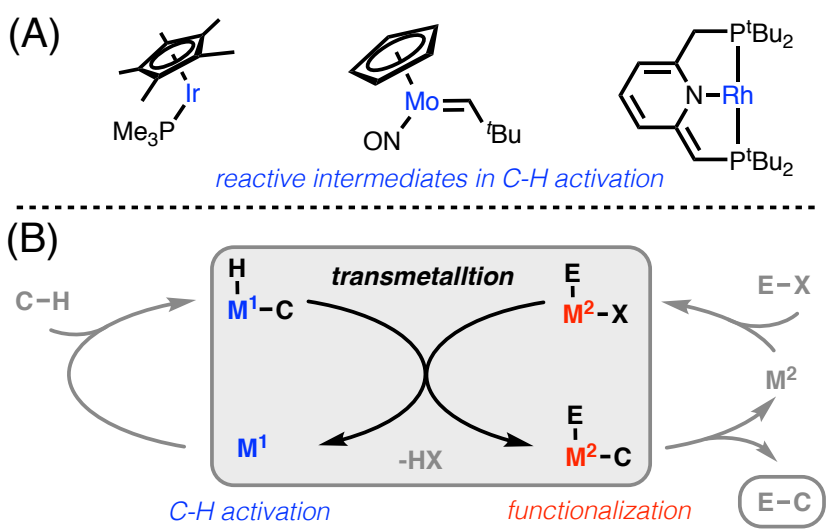

Figure 1. (A) Intermediates capable of mild, non-directed C-H activation; (B) proposed dual catalytic cycle to enable turnover of activated fragments in (A).

The general transformation in Figure 2A summarizes the transmetallation reactivity examined in this work; namely, transfer of a hydrocarbyl ligand $(\mathrm{R})$ to $(\operatorname{cod}) \mathrm{Pt}(\mathrm{Me})(\mathrm{TFA})(\mathbf{1})$ from a variety of organometallic complexes $(\operatorname{cod}=$ cyclooctadiene, $\mathrm{TFA}=$ trifluoroacetate). Rhodium and iridium complexes supported by $\mathrm{Cp}^{*}\left(\mathrm{PMe}_{3}\right)$ are capable of cleaving the $\mathrm{C}-\mathrm{H}$ bonds of numerous alkanes, including methane, via the corresponding intermediate in Figure 1A. Related rhodium (2) and iridium (3) complexes are suitable methyl group donors to (cod) $\mathrm{Pt}(\mathrm{Me})(\mathrm{TFA})$ (Figure $2 \mathrm{~B})$. Related iridium dibenzyl complexes $(\mathbf{4 a}-\mathbf{e})$ transfer benzyl groups at elevated temperature $\left(70^{\circ} \mathrm{C}\right)$ and the mixed phenylbenzyl complex (5) undergoes selective transmetallation for the benzyl ligand over the phenyl ligand. Benzyl ligand transfer from molybdenum (6) and tungsten (7) complexes supported by $(\mathrm{Cp})(\mathrm{NO})$, on the other 
hand, highlights the diversity of compatible organometallic hydrocarbyl donors. Like $\mathrm{Cp}^{*}\left(\mathrm{PMe}_{3}\right) \mathrm{Rh} / \mathrm{Ir}$ complexes, $(\mathrm{Cp})(\mathrm{NO}) \mathrm{Mo} / \mathrm{W}$ complexes are also capable of activating various hydrocarbons, but do so via alkylidene intermediates like that shown in Figure 1A. Transmetallation of methyl and benzyl ligands was also achieved from the square planar rhodium pincer complexes $\mathbf{8}$ and $\mathbf{9}$, respectively, which harness metal-ligand cooperativity to cleave $\mathrm{C}-$ $\mathrm{H}$ bonds via the dearomatized intermediate in Figure $1 \mathrm{~A} \cdot{ }^{2 b, 8}$ The three distinct reactive intermediates in Figure $1 \mathrm{~A}$ underscore the diverse geometries and reactivities of organometallic complexes related to $\mathrm{C}-\mathrm{H}$ activation that are suitable alkyl group donors in transmetallation to $\mathbf{1}$.
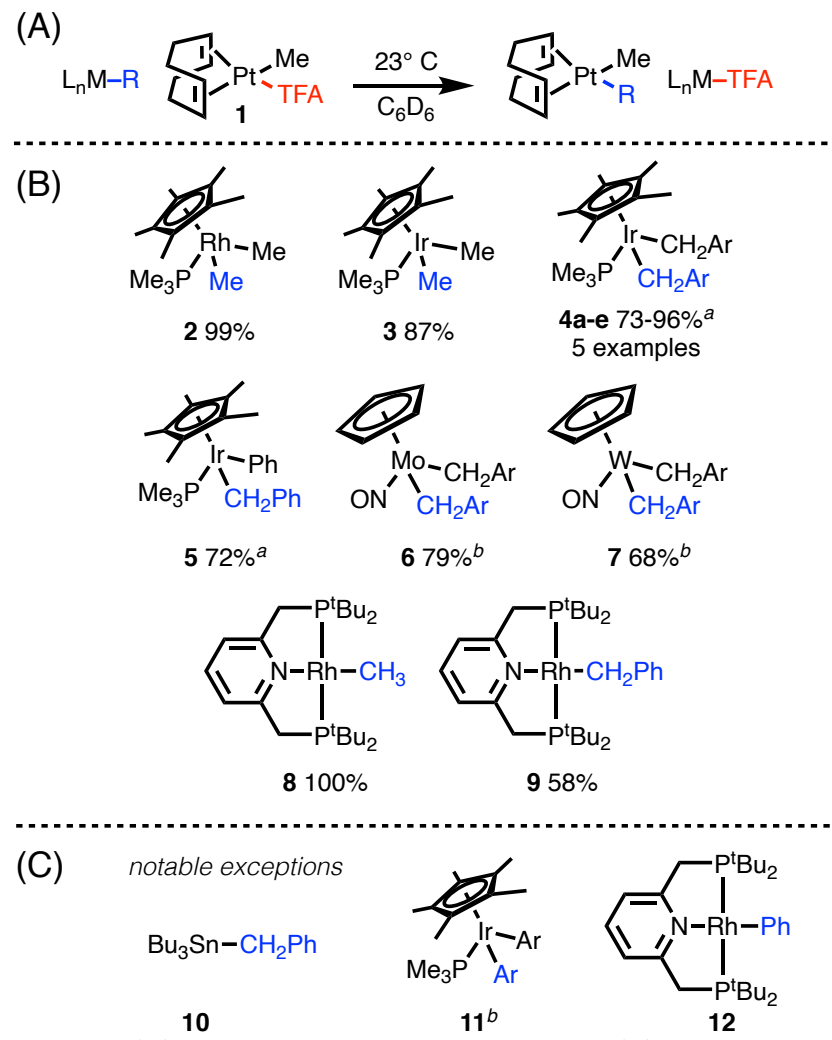

Figure 2. (A) Transmetallation reaction outline; (B) Scope of transition metal nucleophiles in transmetallation to (cod) $\mathrm{Pt}(\mathrm{Me})$ (TFA) and yield of hydrocarbyl group transfer ( ${ }^{a}$ reactions conducted at 70 ${ }^{\circ} \mathrm{C},{ }^{b} \mathrm{Ar}=p$-tolyl).

Despite this broad scope, the incompatible donors (10-12) highlight notable gaps in our understanding of this transformation (Figure $2 \mathrm{C}$ ). In contrast to the transition metal complexes in Figure 2B, tributyl(benzyl)stannane (10)-a prototypical reagent for benzyl group transfer-afforded no transmetallation under the same reaction conditions (Figure $2 \mathrm{C}$ ). ${ }^{9}$ This unexpected difference in reactivity suggests that transition metal donors may exhibit complementary reactivity patterns relative to main group organometall(oid) reagents. For example, whereas tin based reagents favor $\mathrm{sp}^{2}$ transmetallation (e.g. selective phenyl group transfer from $\mathrm{Bu}_{3} \mathrm{SnPh}$ ), 5 afforded selective $\mathrm{sp}^{3}$ group transfer. ${ }^{9}$ Importantly, organometallic complexes in Figure 2 bearing only $\mathrm{sp}^{2}$ hydrocarbyl fragments (11 and 12) were not reactive toward phenyl group transfer to (cod) $\operatorname{Pt}(\mathrm{Me})(\mathrm{TFA})$.
The lack of phenyl group transfer posed a challenge to further development of the dual catalytic cycle proposed in Figure 1 because the relevant intermediates are more reactive toward $\mathrm{sp}^{2} \mathrm{C}-\mathrm{H}$ bond activation. ${ }^{2} \mathrm{~A}$ central objective of this work, therefore, was to better understand $\mathrm{sp}^{3}$ hydrocarbyl group transfer between transition metals and to leverage those insights to enable transmetallation of aryl ligands generated via $\mathrm{C}-\mathrm{H}$ activation (Figure 1 ).

Pioneering studies by Stille revealed that transmetallation to Pd(II) is faster for benzyl stannanes bearing electron withdrawing substituents. ${ }^{9}$ In contrast to transmetallation from tin, we hypothesized, on the basis of prior kinetic studies demonstrating the role of a cationic intermediate $\left((\operatorname{cod}) \mathrm{Pt}(\mathrm{Me})^{+}\right)$, that electron withdrawing substituents would suppress transmetallation from $[\mathrm{Ir}]\left(\mathrm{CH}_{2} \mathrm{Ar}\right)_{2}$ by destabilizing positive charge build up in the transmetallation transition state. ${ }^{3}$ Consistent with this hypothesis, the five substrates tested followed the general trend expected for a transition state with positive charge buildup ( $\mathrm{k}_{\text {rel }} m-\mathrm{F} \cong p-\mathrm{F}<\mathrm{H}<m-\mathrm{Me} \cong p-\mathrm{Me}$ ) (Figure 3A). Notably, however, the relative rates did not obey a linear free energy relationship-perhaps a consequence of the fact two inequivalent benzyl fragments are varied in each experiment. The same trend was observed in transmetallation of the same five iridium substrates to a catalytic palladium electrophile (Figure 3B). Overall these results support the hypothesis that transmetallation from iridium hydrocarbyl donors to platinum(II) and palladium(II) proceeds with a developing positive charge in the group transfer transition state. ${ }^{3}$

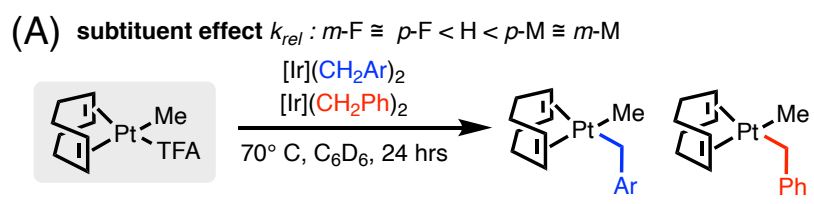

(B) subtituent effect $k_{r e l}: m-\mathrm{F} \cong p-\mathrm{F}<\mathrm{H}<p-\mathrm{M} \cong m-\mathrm{M}$

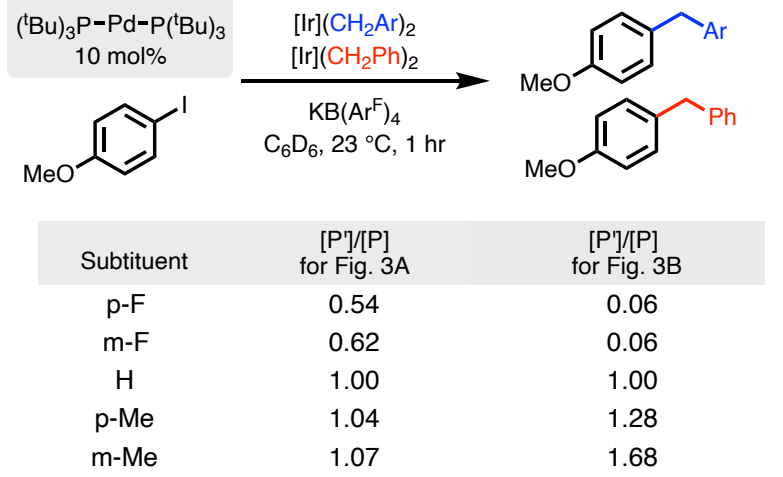

Figure 3. Substituent effect competition experiment reveals faster transmetallation from more electron rich substituents.

With a better understanding of the electronic requirements of hydrocarbyl group transfer between transition metals, we next sought to probe the geometry of the group transfer transition state via a stereochemical probe. The deuterium labeled neohexyl ligand in Figure 4 can be used to assess the stereochemical course of transmetallation via the diagnostic difference in ${ }^{3} \mathrm{JH}_{\mathrm{HH}}$ coupling constants for syn versus anti. ${ }^{2 c, 10}$ Although the stereochemistry of transmetallation to $\mathrm{Pt}(\mathrm{II})$ was obscured by beta-hydride elimination (see supporting information S14 for details), ${ }^{11}$ transmetallation to $\mathrm{Hg}$ (II) revealed retention of stereochemistry consistent with a bent $3 \mathrm{c} 2 \mathrm{e}$ bimolecular 
electrophilic substitution transition state (Figure 4). ${ }^{12}$ Notably, the transmetallation from tetraalkyl stannanes to $\mathrm{Pd}(\mathrm{II})$ proceeds with inversion of stereochemistry. ${ }^{13}$ The contrasting stereochemistry of transmetallation from iridium versus tin again highlights the complementary outcomes observed in transmetallation from transition metals versus main group metalloids.

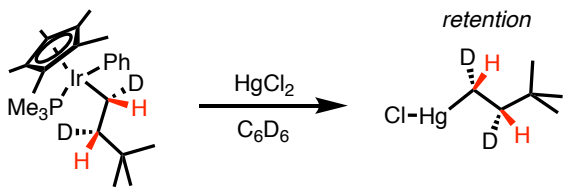

Figure 4. Stereochemical probe reveals transmetallation with retention of stereochemistry.

Given the chemical diversity of the hydrocarbyl donors in Figure 2, it is perhaps not surprising that group transfers from these complexes proceed with widely varying rates. Across the complexes surveyed, benzyl group transfer was slower than even the slowest methyl group transfer (from $[\mathrm{Ir}](\mathrm{Me})_{2}$, Figure 5). The substituent effects presented in Figure 3, which are consistent with positive charge buildup in the transmetallation transition state, suggest that benzyl ligands should undergo faster transmetallation than methyl ligands due the greater ability of benzyl groups to stabilize positive charge buildup. ${ }^{4}$ On the contrary, transmetallation of methyl group was much faster than that of benzyl groups, consistent with steric effects dominating the relative rates of methyl versus benzyl group transfer.

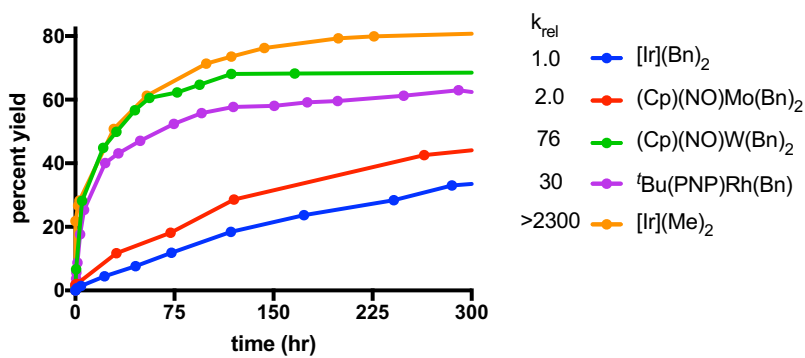

Figure 5. Product formation versus time in transmetallation of benzyl fragments to (cod) $\mathrm{Pt}(\mathrm{Me})(\mathrm{TFA})$ with the slowest methyl transmetallation included for comparison. Reactions were ran in $\mathrm{C}_{6} \mathrm{D}_{6}$. $\mathrm{k}_{\text {rel }}$ numbers were approximated based on these data.

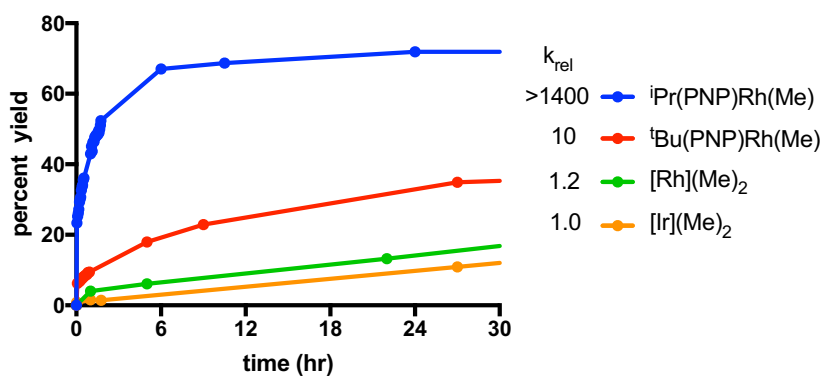

Figure 6. Product formation versus time in transmetallation of methyl fragments to (cod) $\mathrm{Pt}(\mathrm{Me})(\mathrm{Cl})$. Reactions were ran in $\mathrm{C}_{6} \mathrm{D}_{6} . \mathrm{k}_{\mathrm{rel}}$ numbers were approximated based on these data.
Striking differences were also observed in the relative conversion versus time profiles of methyl group transfer as illustrated in Figure 6. Notably, the coordinatively unsaturated rhodium pincer complex ${ }^{\mathrm{t}} \mathrm{Bu}(\mathrm{PNP}) \mathrm{Rh}(\mathrm{Me})$ gave dramatic rate acceleration relative to coordinatively saturated $[\mathrm{Ir} / \mathrm{Rh}](\mathrm{Me})_{2}$. We previously observed a 100 fold increase in initial rates of $\mathrm{C}-\mathrm{H}$ activation upon modifying the ${ }^{\mathrm{t}} \mathrm{Bu}(\mathrm{PNP})$ ligand to ${ }^{\mathrm{P}} \mathrm{Pr}(\mathrm{PNP})$ and hypothesized that such a modification could afford rate acceleration for transmetallation. ${ }^{7}$ Much faster methyl group transfer was observed with ${ }^{i} \operatorname{Pr}(\mathrm{PNP}) \mathrm{Rh}(\mathrm{Me})$ relative to ${ }^{\mathrm{t}} \mathrm{Bu}(\mathrm{PNP}) \mathrm{Rh}(\mathrm{Me})$.

The faster transmetallation observed with the ${ }^{i} \operatorname{Pr}(\mathrm{PNP})$ ligand scaffold, relative to ${ }^{t} \mathrm{Bu}(\mathrm{PNP})$, enabled transfer of phenyl groups from ${ }^{i} \operatorname{Pr}(\mathrm{PNP}) \mathrm{Rh}(\mathrm{Ph})$ to (cod)Pt(Me)(TFA) and a variety of other metal(loid) complexes as illustrated in Figure 7. The reaction proceeds with trifluoroacetate, methanesulfonate, and chloride leaving groups and tolerates aromatic ancillary ligands (Figure 7A-D). Notably, transmetallation is not limited to platinum complexes chelated by cod; for example, iPr(PNP) $\mathrm{Rh}(\mathrm{Ph})$ generated an organometalloid nucleophile by phenyl group transfer to trimethylstannane chloride (Figure 7F). The SPhos complex in Figure 7E reacted to give phenyl group transfer and subsequent reductive elimination, ${ }^{14}$ which also appears to be the first time a Buchwald ligand has been reported to coordinate to $\mathrm{Pt}(\mathrm{II})$ (Figure 8).

(A)

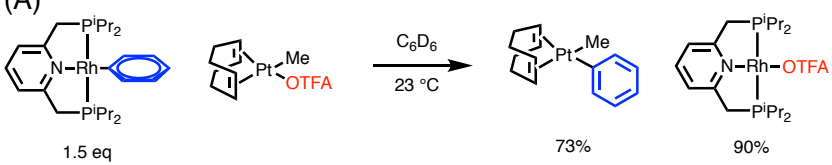

(B)

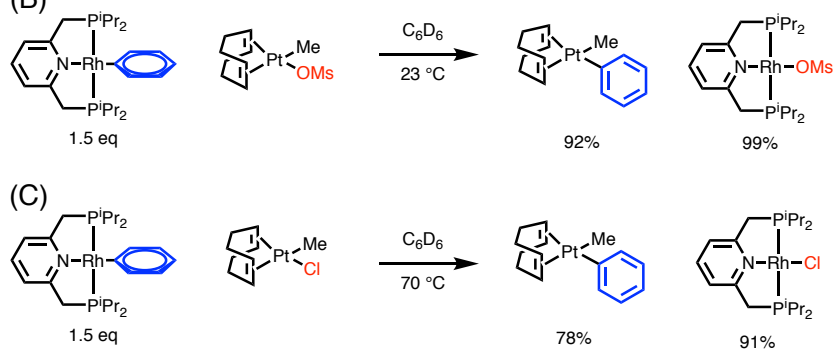

(D)

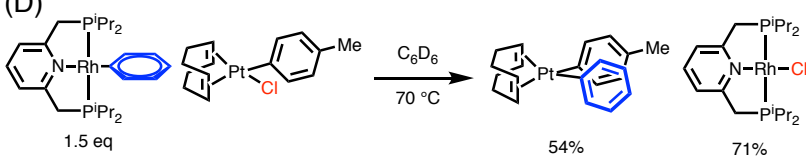

(E)

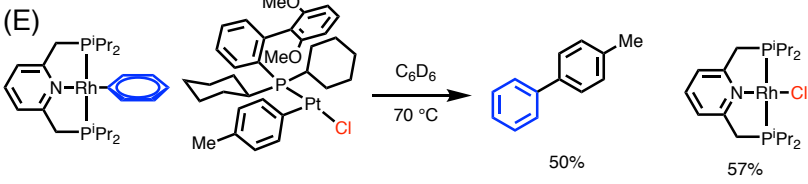

(F)

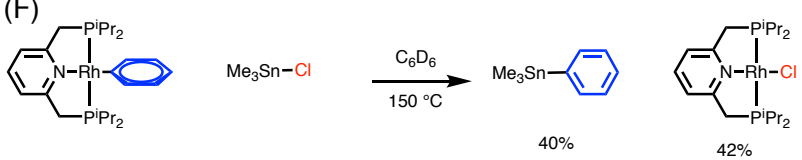

Figure 7. Scope of phenyl group transfer from ${ }^{\mathrm{i}} \mathrm{Pr}(\mathrm{PNP}) \mathrm{Rh}(\mathrm{Ph})$ to metal(loid) 


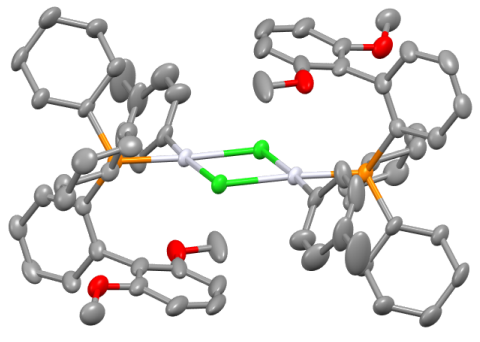

Figure 8. Crystal structure of $(\mathrm{SPhos}) \mathrm{Pt}(p-\mathrm{Tol})(\mathrm{Cl})$. The complex was recrystallized as dimers.

Overall, our study of the scope of hydrocarbyl group transfer between transition metals reveals that a variety of organometallic species relevant to $\mathrm{C}-\mathrm{H}$ activation are capable of transferring hydrocarbyl fragments to $\mathrm{Pt}$ (II) electrophiles. ${ }^{15}$ A substituent effect study indicates that electron rich hydrocarbyl fragments are transferred more rapidly that electron poor fragments. Finally, a stereochemical probe demonstrates that hydrocarbyl group transfer proceeds with retention of stereochemistry, consistent with a bent $3 \mathrm{c} 2 \mathrm{e}$ bimolecular electrophilic substitution transition state. As a whole, these studies shed light on the scope and molecular details of hydrocarbyl group transfer between transition metals. These findings will be useful in the development of dual catalytic systems that leverage stoichiometric organometallic reactions for new catalytic transformations via transmetallation of activated fragments between transition metals with complementary reactivity.

\section{ASSOCIATED CONTENT}

Supporting Information

The Supporting Information is available free of charge on the ACS Publications website:

Synthetic and computational procedures (PDF)

Coordinates of calculated structures (XYZ)

\section{Accession Codes}

CCDC 2016679 and 2016680 contain the supplementary crystallographic data for this paper. These data can be obtained free of charge via www.ccdc.cam.ac.uk/data_request/cif, or by emailing data_request@ccdc.cam.ac.uk, or bycontacting The Cambridge Crystallographic Data Centre, 12 Union Road, Cambridge CB2 1EZ, UK; fax: +441223336033.

\section{AUTHOR INFORMATION}

\section{Corresponding Author}

*E-mail for J.C.L.: jcl3@iu.edu.

\section{ORCID}

Jared C. Lewis: 0000-0003-2800-8330

Natalie H. Chan: 0000-0002-0816-0848

Notes

The authors declare no competing financial interest.

\section{ACKNOWLEDGMENT}

We would like to thank Dr. Landon Durak for synthesis of [Rh] $\mathrm{Me}_{2}$ and Dr. Alexander Filatov for assistance with crystal structure determination. This work was supported by the NSF under the CCI Center for Selective C-H Functionalization (CCHF, CHE-1205646). JJG was supported by an NSF predoctoral fellowship (DGE-1144082). This work was completed in part with resources provide by the University of Chicago Research Computing Center. Use of the Advanced Photon Source, an Office of Science User Facility operated for the U.S. Department of Energy (DOE) Office of Science by Argonne National Laboratory, was supported by the U.S. DOE under contract No. DE-AC0206miltCH11357. ChemMatCARS Sector 15 is principally supported by the Divisions of Chemistry (CHE) and Materials Research (DMR), National Science Foundation, under grant number NSF/CHE-1346572. Use of the PILATUS3 X CdTe $1 \mathrm{M}$ detector is supported by the National Science Foundation under grant num-ber NSF/DMR-1531283.

\section{REFERENCES}

(1). (a) For representative examples of $\mathrm{C}-\mathrm{H}$ activations: Bengali, A.; Arndtsen, B.; Burger, P.; Schultz, R.; Weiller, B.; Kyle, K.; Moore, C.; Bergman, R. G. Pure Appl. Chem. 1995, 67, 281-288. (b) Shilov, A. E.; Shulpin, G. B. Chem. Rev. 1997, 97, 2879-2932. (c) Labinger, J. A.; Bercaw, J. E. Top. Organomet. Chem. 2011, 35, 29-60. For more recent reviews of $\mathrm{C}-\mathrm{H}$ functionalization: (d) Hartwig, J. F. J. Am. Chem. Soc. 2016, 138, 2-24. (e) Davies, H. M. L.; Morton, D. J. Org. Chem. 2016, 81 (2), 343. (f) Hartwig, J. F.; Larsen, M. A. ACS Cent. Sci. 2016, 2 (5), 281. (g) Abrams, D. J. ; Provencher, P. A.; Sorensen, E. J. Chem. Soc. Rev. 2018, 47, 8925-8967.

(2). (a) Pamplin, C. B.; Legzdins, P. Acc. Chem. Res. 2003, 36, 223-233.(b) Schwartsburd, L.; Iron, M. A.; Konstantinovski, L.; Ben-Ari, E.; Milstein, D. Organometallics 2011, 30, 2721-2729. (c) Janowicz, A. H.; Bergman, R. G. J. Am. Chem. Soc. 1983, 105, 3929-3939.

(3). Durak, L. J.; Lewis, J. C. Organometallics 2013, 32, 3153-3156.

(4). Durak, L. J.; Lewis, J. C. Organometallics 2014, 33, 620-623.

(5). (a) Wang, D.; Izawa, Y.; Stahl, S. S. J. Am. Chem. Soc. 2014, 136, 9914-9917. (b) Lee, S. Y.; Hartwig, J. F. J. Am. Chem. Soc. 2016, 138, 15278-15284. (c) Li, W.; Yuan, D.; Wang, G.; Zhao, Y.; Xie, J.; Li, S.; Zhu, C. J. Am. Chem. Soc. 2019, 141, 3187-3197.

(6). For reviews on transmetallations between two transition metals complexes: (a) Osakada, K.; Yamamoto, T. Coordination Chemistry Reviews 2000, 198 (1), 379-399. (b) Suzaki, Y.; Yagyu, T.; Osakada, K. Journal of Organometallic Chemistry 2007, 692, 326-342. (c) Hirner, J. J.; Shi, Y.; Blum, S. A. Acc. Chem. Res. 2011, 44 (8), 603. (d) Pérez-Temprano, M. H.; Casares, J. A.; Espinet, P. Chem. Eur. J. 2012, 18 (7), 1864. For a few notable recent examples: (e) Smith, S. E.; Sasaki, J. M.; Bergman, R. G.; Mondloch, J. E.; Finke, R. G. J. Am. Chem. Soc. 2008, 130, 1839-1841. (f) Huang, L.; Ackerman, L. K. G.; Kang, K.; Parsons, A. M.; Weix, D. J. J. Am. Chem. Soc. 2019, 141, 10978-10983.

(7). Gair, J. J.; Qiu, Y.; Chan, N. H.; Filatov, A. S.; Lewis, J. C. Organometallics 2017, 36, 4699-4706.

(8). (a) Khusnutdinova, J. R.; Milstein, D. Angew. Chem. Int. Ed. 2015, 54, 12236-12273. (b) Milstein, D. Phil. Trans. R. Soc. A 2015, 373, 20140189. (c) Gunanathan, C.; Milstein, D. Acc. Chem. Res. 2011, 44, 588-602. (d) Gunanathan, C.; Milstein, D. Top. Organomet. Chem. 2011, $37,55-84$

(9). (a) Labadie, J. W.; Stille, J. K. J. Am. Chem. Soc. 1983, 105, 6129-6137. (b) For example, it has been shown that the relative rate of $\mathrm{Ph}:$ Me transfer to mercury(II) salts is ca. 400-500:1. Abraham, M. H.; Sedaghat- Herati, M. R. J. Chem. Soc., Perkin Trans. 2 1978, 729.

(10). Peterson, T. H.; Golden, J. T.; Bergman, R. G. Organometallics 1999, 18 (10), 2005-2020.

(11). For an example of similar scrambling: Bock, P. L.; Boschetto, D. J.; Rasmussen, J. R.; Demers, J. P.; Whitesides, G. M. J. Am. Chem. Soc. 1974, 96 (9), 2814-2825.

(12). For literature ${ }^{1} \mathrm{H}$ NMR values of the resulting mercury compounds: (a) Bergbreiter, D. E.; Rainville, D. P.J. Organomet. Chem. 1976, 121, 19-23. For other studies of stereochemistry of metal-carbon bond cleavage by $\mathrm{Hg}$ (II) and other soft electrophiles: See ref. (10), and (b) Dong, D.; Slack, D. A.; Baird, M. C. Inorg. Chem. 1979, 18 (1), 188-191. 
(13). Labadie, J. W.; Stille, J. K. J. Am. Chem. Soc. 1983, 105, 669-670.

(14). (a) Barder, T. E.; Walker, S. D.; Martinelli, J. R; Buchwald, S. L. J. Am. Chem. Soc. 2005, 127, 4685-4696. (b) Martin, R; Buchwald, S. L. Acc. Chem. Res. 2008, 41, 1461-1473.
(15). It has also been shown that the $[\mathrm{Rh}]$ complexes can act as a metallic Lewis base to bind Lewis acidic organozinc complexes. Gair, J. J.; Qiu, Y.; Khade, R. L.; Chan, N. H.; Filatov, A. S.; Zhang, Y.; Lewis, J. C. Organometallics 2019, 38, 1407-1412.

\section{TOC Graphic:}

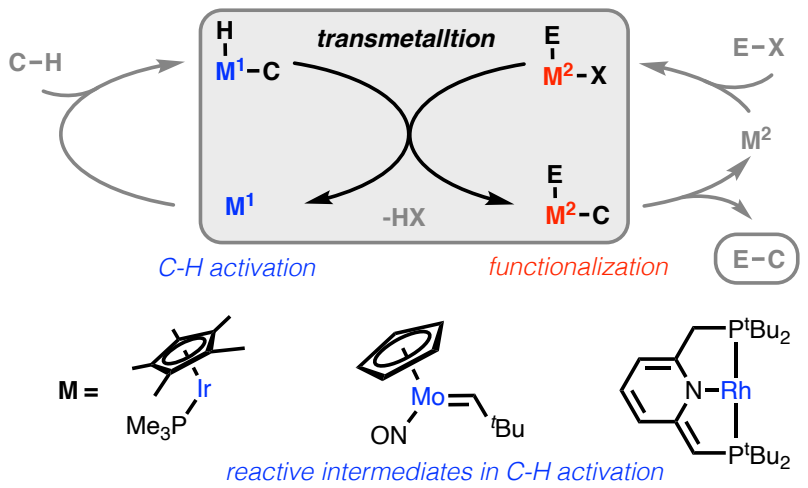

